Check for updates

The BMJ

Cite this as: $B M J$ 2021;374:n1958 http://dx.doi.org/10.1136/bmj.n1958 Published: 05 August 2021

\section{Covid-19: All 16 and 17 year olds in the UK to be offered first vaccine dose}

\section{Elisabeth Mahase}

All 16 and 17 year olds in the UK will be offered a first dose of the Pfizer BioNTech covid-19 vaccine, the Joint Committee on Vaccination and Immunisation (JCVI) has announced.

The committee has not yet decided, however, when the second dose will be offered. Instead, it will continue to examine the emerging evidence over the next few weeks to determine the best dosing interval, which will probably be within 12 weeks of the first, it is understood.

Speaking at a televised press conference on 4 August, JCVI chair Wei Shen Lim said that the committee had considered the benefits and risks of vaccination to individuals rather than to wider society, and concluded that the benefits outweighed any risks in this age group. Previously, only 16 and 17 year olds considered at risk of severe covid illness were able to get the vaccine. ${ }^{1}$

He said, "We are now seeing young people who are unvaccinated being admitted to hospital with quite severe covid. Many of them need oxygen support and, sadly, some of them also need a machine to help them to breathe. Much of that suffering can be prevented or reduced through vaccination."

The JCVI has estimated that one vaccine dose will provide young people with at least $80 \%$ protection against hospital admission with covid-19.

Last month the committee announced that children aged 12-15 who are at increased risk of serious illness from infection with SARS-CoV-2 will be offered the Pfizer BioNTech vaccine.

The updated advice from the JCVI comes as the Office for National Statistics has estimated that over or around 9 in 10 adults in all four UK nations would have tested positive for antibodies against SARS-CoV-2 on a blood test in the week beginning 12 July 2021, suggesting they had the infection in the past or have been vaccinated. ${ }^{2}$ The report said that "there is a clear pattern between vaccination and testing positive for covid-19 antibodies."

\section{Unacceptable delay}

Deepti Gurdasani, a clinical epidemiologist and senior lecturer in machine learning at Queen Mary University of London, welcomed the JCVI's decision but said the delay has been "unacceptable, given the Pfizer vaccine was approved by the Medicines and Healthcare Products Regulatory Agency for those 16 years old and over in December, and the benefit versus risk has been clear for a while.”

Gurdasani is one of 18 scientists who has authored a risk benefit analysis paper on vaccinating teenagers-made available as a preprint while it is being reviewed for publication ${ }^{3}$ - which has argued that the "benefits of offering vaccination to all 12 to 17 year olds clearly outweigh the risks."

Using a US Centers for Disease Control and Prevention analysis as a template, the group examined the potential benefits and risks of offering vaccines to England's 3.9 million 12 to 17 year olds ahead of school reopening in September. They used extracted data on the number of young people in this age group in England diagnosed with covid-19 and the related hospital admissions and deaths between July 2020 and March 2021.

Looking at various infection rate scenarios, they reported that vaccination could avert between 4570 hospital admissions (based on late July 2021 infection rates continuing for 16 weeks) and 70 hospital admissions (based on a low incidence scenario of 50 infections per 100 ooo per week)-even after assuming that all cases of vaccine induced myocarditis are admitted to hospital.

For long covid, vaccination could avert 31000 (assuming 8\% incidence) or 16 ooo (assuming 4\% incidence) cases in 12 to 17 year olds, based on the July 2021 infection rates.

The researchers said that the risk of hospital admission with vaccination only exceeds the risk of hospital admission with covid-19 when the case incidence is below 30 per 100 ooo per week-a level not seen in adolescents in the UK in 2021.

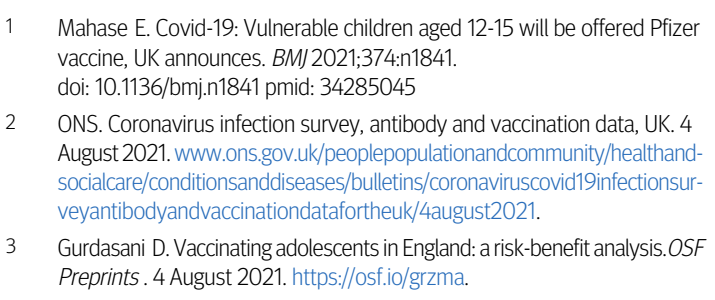

Mahase E. Covid-19: Vulnerable children aged 12-15 will be offered Pfizer vaccine, UK announces. BMJ2021;374:n1841. doi: 10.1136/bmj.n1841 pmid: 34285045

2 ONS. Coronavirus infection survey, antibody and vaccination data, UK. 4 August 2021. www.ons.gov.uk/peoplepopulationandcommunity/healthand socialcare/conditionsanddiseases/bulletins/coronaviruscovid19infectionsurveyantibodyandvaccinationdatafortheuk/4august2021.

3 Gurdasani D. Vaccinating adolescents in England: a risk-benefit analysis.OSF Preprints. 4 August 2021. https://osf.io/grzma.

This article is made freely available for use in accordance with BMJ's website terms and conditions for the duration of the covid-19 pandemic or until otherwise determined by BMJ. You may use, download and print the article for any lawful, non-commercial purpose (including text and data mining) provided that all copyright notices and trade marks are retained. 